\title{
Lithium barrier materials for on-chip Si-based microbatteries
}

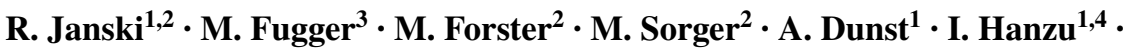 \\ M. Sternad ${ }^{1} \cdot$ M. Wilkening ${ }^{1,4}$
}

Received: 20 April 2017 / Accepted: 8 June 2017 / Published online: 15 June 2017

(c) The Author(s) 2017. This article is an open access publication

\begin{abstract}
The integration of lithium-ion batteries, featuring ultra-high discharge rates, directly into silicon-based semiconductor devices opens unique paths towards the development of new mobile micro-electronics applications. Nevertheless, the small and mobile lithium ions have to be confined within the battery area of the silicon chip, otherwise the nearby fine microelectronics devices will be irreversibly damaged. Hence, a barrier material that blocks $\mathrm{Li}^{+}$ transport from the active components of the battery into the surrounding crystalline $\mathrm{Si}$ is needed. Here we evaluated the capability of magnetron sputtered barrier films of nitrides and alloys of refractory metals to prevent lithium ion diffusion and, thus, the formation of $\mathrm{Li}-\mathrm{Si}$ phases outside the battery area. In order to determine the Li profiles in the barrier layer and in the silicon substrate, time-of-flight secondary ion mass spectroscopy was applied for profiling the first microns. In combination with electrochemical testing it turned out that titanium nitride as well as tantalum nitride barriers are able to significantly block Li ion migration.
\end{abstract}

R. Janski

rafael.janski@infineon.com

M. Wilkening

wilkening@tugraz.at

1 Christian Doppler Laboratory for Lithium Batteries, Institute for Chemistry and Technology of Materials, Graz University of Technology, 8010 Graz, Austria

2 Infineon Technologies Austria AG, 9500 Villach, Austria

3 Institute of Chemical Technologies and Analytics, Vienna University of Technology, 1040 Vienna, Austria

4 ALISTORE-ERI European Research Institute, 33 rue Saint Leu, 80039 Amiens, France

\section{Introduction}

Mobile autonomous microelectronic devices are already indispensable to our daily life. Applications based on wireless radio-frequency identification devices (RFID) have reached a high degree of sophistication and pervasiveness, ranging from smart cards and tracking devices to advanced medical technologies. Significant issues and limitations are hitherto related to powering the RFID devices [1]. Besides the possibility of energy harvesting, e.g., via photovoltaic cells or by using the interrogation RF radiation itself, the most commonly used power sources are batteries [2, 3]. In the case of microelectronics, the use of lithium-ion batteries requires miniaturized integrated units. Lithium-ion (micro-)batteries with solid electrolytes can be prepared via high temperature processing techniques; they are, however, limited in power density [4-8]. Alternatively, one may consider miniaturized batteries with liquid electrolytes [9, 10]; these systems may provide pulsed currents as high as $100 \mathrm{~mA} \mathrm{~cm}^{-2}$.

Independent from the electrolyte used, the high power capability of a battery relies on the fast transport of lithium ions through its various components. Indeed, owing to the small ionic radius and low mass of lithium ions they tend to diffuse in many materials, including silicon. The corresponding diffusion coefficient values span over many orders of magnitude. Lithium ion transport by diffusion, even in minute quantities, represents a permanent risk for the functioning and reliability of semiconductor products. If contaminated with lithium ions from the battery region, the whole device is expected to suffer damage. Furthermore, if directly integrated on a chip, the loss of $\mathrm{Li}^{+}$through diffusion across the boundaries of a battery would cause an irreversible decrease of the charge capacity. Therefore, when placing a lithium-ion battery onto a semiconductor 
substrate an efficient barrier is needed to prevent the mobile $\mathrm{Li}$ ions to diffuse into the regions outside the battery. In particular, this prevention is of high importance if the housing material is identical with the active material [11]. This combination occurs whenever $\mathrm{Si}$ is used as both the negative electrode [12] and the housing material, i.e., the battery is directly encapsulated into the Si wafer on which the microelectronics device is also realized.

There are three types of possible diffusion barriers [13]. (i) The first and most important group is called a passive diffusion barrier. Materials constituting such a barrier are chemically inert with respect to both sides of the diffusion couple, that is, the host material $(\mathrm{Si})$ and the diffusing species $\left(\mathrm{Li}^{+}\right)$. (ii) The second group can be specified as stuffed barrier systems; stuffing the interfacial regions with other atoms or molecules can greatly reduce the diffusivity of other species. Tungsten-titanium alloys (W-Ti), sometimes with $\mathrm{N}_{2}$ as stuffing agent, are usually used in microelectronic device fabrication to prevent diffusion of, e.g., $\mathrm{Cu}$. (iii) The third group is based on sacrificial materials; the barrier layer, such as titanium, is sacrificed to prevent the reaction of $\mathrm{Li}$ with $\mathrm{Si}$. The function of this type of barrier is limited in lifetime because it consumes $\mathrm{Li}$ ions and thus reduces the capacity of a battery.

Earlier studies focused on adequate barriers for solidstate systems rather than lithium-ion batteries relying on liquid electrolytes [10]. Virtually no experimental information is available about what would be best suited for onchip Li-ion microbatteries. Depending on the characteristics of a given battery, the barrier has to satisfy certain requirements in terms of effectiveness, producibility, i.e., implementation, and lifetime. The overall ion dynamics of a microbattery with $\mathrm{Li}^{+}$as charge carrier, meaning both the desired and undesired transport phenomena as well as the underlying reaction kinetics, strongly depends on the materials chosen to construct the battery and to encapsulate it. As it has been shown by Notten et al. [14], TiN and TaN turned out to be promising blocking materials. Cyclic voltammetry has revealed that nitrides seem to be indeed electrochemically stable against $\mathrm{Li}$ metal. We know from semiconductor industry that $\mathrm{W}-\mathrm{Ti}$ is an excellent barrier with respect to in-diffusion of $\mathrm{Cu}$ ions. To our knowledge, there is, however, no information available about its ability to block Li ion diffusion effectively.

Here we evaluated the properties of Ta, TaN, TiN and a W-Ti alloy to act as barriers in miniaturized Si-based lithium-ion batteries having a liquid electrolyte. The barrier materials were characterized electrochemically using cyclic voltammetry and time-of-flight secondary ion mass spectroscopy (ToF SIMS) depth profiling, in particular.

\section{Experimental}

\subsection{Sample preparation}

Boron doped (100) Si with a nominal resistivity of $8 \mathrm{~m} \Omega \mathrm{cm}$ was used as substrate. The substrates were cleaned and thinned to $400 \mu \mathrm{m}$. A copper current collector was applied to the backside via sputtering (see Fig. 1) $\mathrm{Ta}, \mathrm{TaN}$, and TiN as well as a tungsten-titanium alloy with an atomic ratio $\mathrm{W}: \mathrm{Ti}$ of 80:20 respectively were used as potential barrier layers. These layers were deposited with PVD-sputter equipment and had a thickness of $50 \mathrm{~nm}$. The sputtering base pressure was less than approximately $3 \times 10^{-7}$ mbar, with an argon or argon/nitrogen process gas flow for reactive sputtering. The procedure is described in Table 1 in more detail.

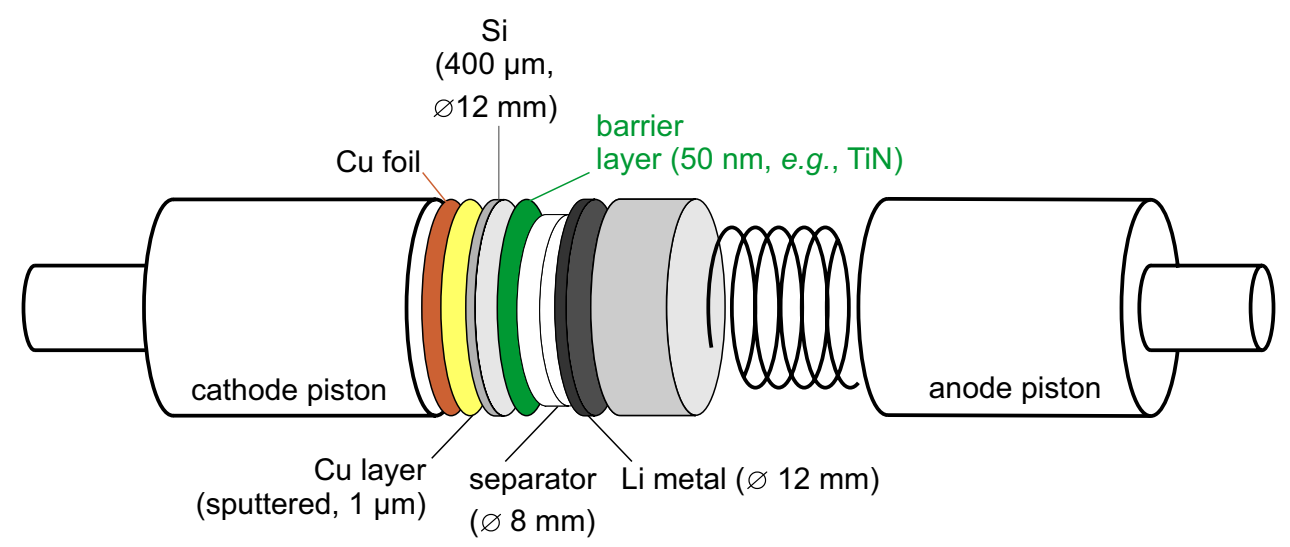

Fig. 1 Setup of the Li ion half-cell used to test the blocking property of several barrier layers. The barrier layer (50 $\mathrm{nm}$ in thickness) is shown in green; it was placed on top of the Si electrode $(400 \mu \mathrm{m}$, grey). Backside: sputtered $\mathrm{Cu}$ layer (1 $\mu \mathrm{m}$ in thickness, yellow color), between this thin $\mathrm{Cu}$ layer and the cathode piston a $\mathrm{Cu}$ foil (orange) secures electrical contact. The whole system was placed in a stainless steel Swagelok ${ }^{\circledR}$-type cell. See text for further explanation. (Color figure online) 
Table 1 Processing parameters used for the deposition of the barrier layers (W-Ti, TiN, TaN and Ta) with a TRIKON "Sigma fxP PVD" sputtering tool

\begin{tabular}{|c|c|c|c|c|c|c|}
\hline \multirow[t]{2}{*}{ Barrier material } & \multirow[t]{2}{*}{ Sputter target 8 inch } & \multirow[t]{2}{*}{ Base pressure (mbar) } & \multirow{2}{*}{$\begin{array}{l}\text { Target power } \\
(\mathrm{kW})\end{array}$} & \multirow{2}{*}{$\begin{array}{l}\text { Chamber pressure } \\
\text { (mbar) }\end{array}$} & \multicolumn{2}{|c|}{ Process gas flow } \\
\hline & & & & & $\operatorname{Ar}(\mathrm{sccm})$ & $\mathrm{N}_{2}(\mathrm{sccm})$ \\
\hline $\mathrm{W}-\mathrm{Ti}$ & Tungsten/titanium & $2.6 \times 10^{-7}$ & 2 & $3.0 \times 10^{-3}$ & 50 & 0 \\
\hline TiN & Titanium & $1.3 \times 10^{-7}$ & 12 & $1.8 \times 10^{-3}$ & 50 & 70 \\
\hline $\mathrm{TaN}$ & Tantalum & $2.6 \times 10^{-7}$ & 15 & $2.0 \times 10^{-3}$ & 100 & 70 \\
\hline $\mathrm{Ta}$ & Tantalum & $2.0 \times 10^{-7}$ & 15 & $2.0 \times 10^{-3}$ & 100 & 0 \\
\hline
\end{tabular}

Mechanical as well as structural properties of the barrier layers deposited were investigated with a film stress measurement according to Stoney Eq. [15] using an MX-NT bow measurement tool (Eichhorn Hausmann $\mathrm{GmbH}$, Karlsruhe). This method is commonly employed in semiconductor industry to characterize deposited layers by measuring the wafer bow caused by internal layer stress. To characterize the bulk behavior of the materials, cross sections of the samples were prepared with a FEI Vion ${ }^{\mathrm{TM}}$ Plasma focused ion beam (FIB) system or simply by breaking the sample. Scanning electron microscopy (SEM) pictures were taken with a S-5200 Ultra-High Resolution Hitachi FE SEM. For all experiments round samples with a diameter of $12 \mathrm{~mm}$ were used. These samples were obtained from the 8 -inch wafers by mechanical drilling.

\subsection{Electrochemical testing}

Electrochemical cells were assembled inside an Argon filled glove box. Water and oxygen impurity levels were kept below $1 \mathrm{ppm}$. All samples, namely bare $\mathrm{Si}$ as well as the $\mathrm{Si}$ samples with barrier layers, were mounted as working electrode in stainless steel Swagelok ${ }^{\circledR}$ cells. In the two-electrode cell setup used, a lithium metal disc (12 $\mathrm{mm}$ in diameter, $380 \mu \mathrm{m}$ in thickness) with a copper current collector foil (12 $\mathrm{mm}$ in diameter, $20 \mu \mathrm{m}$ in thickness) was used as counter electrode. A stack of 12 layers of separator discs ( $8 \mathrm{~mm}$ in diameter, total thickness of $2 \mathrm{~mm}$, Freudenberg 2190) saturated with $80 \mu \mathrm{L}$ of electrolyte solution (1 $\mathrm{M} \mathrm{LiPF}_{6}$ in EC:EMC 3:7) was positioned between the electrodes. The final configuration of the whole stack is shown in Fig. 1.

Cyclic voltammetry (CV) measurements were carried out using a VMP3 instrument (BioLogic Science Instruments). The cells were charged and discharged galvanostatically between 1.5 and $0.05 \mathrm{~V}$ versus $\mathrm{Li} / \mathrm{Li}^{+}$. The $\mathrm{CV}$ measurements of the barrier samples were performed at a scan rate of $30 \mu \mathrm{V} \mathrm{s}^{-1}$.

\subsection{Electrochemical Li ion stressing}

The Swagelok ${ }^{\circledR}$ cell was connected to a Maccor Series 4000 automated test system. Table 2 displays the various steps of the Maccor program to charge and discharge the
Table 2 Test program (12 steps altogether) to study the samples with $\mathrm{Li}$-ion blocking barriers on a MACCOR battery tester

\begin{tabular}{|c|c|c|c|c|c|c|c|}
\hline \multirow[t]{2}{*}{ Step } & \multicolumn{3}{|c|}{ Operation mode } & \multicolumn{2}{|c|}{ Limitation } & \multicolumn{2}{|c|}{ Termination criteria } \\
\hline & Name & Type & Value & Type & Value & Type & Value \\
\hline 1 & Rest & Time & & & & Time & $12 \mathrm{~h}$ \\
\hline 2 & Charge & Current & $140 \mu \mathrm{A}$ & Voltage & $20 \mathrm{mV}$ & Time & $1 \mathrm{~h}$ \\
\hline 3 & Rest & Time & & & & Time & $12 \mathrm{~h}$ \\
\hline 4 & Charge & Current & $140 \mu \mathrm{A}$ & Voltage & $20 \mathrm{mV}$ & $\begin{array}{l}\text { Capacity } \\
\text { Time }\end{array}$ & $\begin{array}{l}5 \mathrm{mAh} \\
6 \mathrm{~h}\end{array}$ \\
\hline 5 & Discharge & Current & $140 \mu \mathrm{A}$ & & & Voltage & $1 \mathrm{~V}$ \\
\hline 6 & Discharge & Voltage & $1 \mathrm{~V}$ & & & Time & $6 \mathrm{~h}$ \\
\hline 7 & Loop start & & & & & & \\
\hline 8 & Charge & Current & $712 \mu \mathrm{A}$ & voltage & $20 \mathrm{mV}$ & $\begin{array}{l}\text { Capacity } \\
\text { Time }\end{array}$ & $\begin{array}{l}5 \mathrm{mAh} \\
6 \mathrm{~h}\end{array}$ \\
\hline 9 & Discharge & Current & $712 \mu \mathrm{A}$ & & & Voltage & $1 \mathrm{~V}$ \\
\hline 10 & Discharge & Voltage & $1 \mathrm{~V}$ & current & $712 \mu \mathrm{A}$ & Time & $6 \mathrm{~h}$ \\
\hline 11 & loop end & & & & & Loop count & 10 \\
\hline 12 & Rest & Time & & & & Time & $24 \mathrm{~h}$ \\
\hline 13 & End & & & & & & \\
\hline
\end{tabular}


cells. Charging experiments were done with at least four samples investigated in parallel whereas all of them were prepared from the same wafer. The samples were carefully chosen in order to avoid scratches of the barrier layers which often occurred because of the mechanical sample cutting process.

An initial $12 \mathrm{~h}$ rest step was used to ensure homogeneous saturation of the separator with electrolyte. Then an initial reducing current $I$ of $140 \mu \mathrm{A}$ was applied while an additional condition was used to limit the voltage across the cell to $20 \mathrm{mV}$. When the voltage limit is reached the initially constant current is lowered so that the voltage limitation is obeyed. A voltage limitation of $20 \mathrm{mV}$ avoided the growth of lithium dendrites at the surface. In the case of an ideal barrier a final value $I=0$ would be expected while the voltage across the cell would stay at $20 \mathrm{mV}$. This step was limited to $1 \mathrm{~h}$. Another rest step ensured equilibration of the cell. After that another charging step (attempted lithiation through the barrier layer) was performed ( $6 \mathrm{~h}, 5 \mathrm{mAh})$. The subsequent discharging step $\left(I_{\max }=140 \mu \mathrm{A}\right.$, upper voltage limitation of $1 \mathrm{~V}$ ) complements the formation procedure. The procedure applied ensured a homogeneous formation of the solid electrolyte interface (SEI) [16]. Furthermore, it represents a standardized sequence allowing for a reasonable comparison with the reference sample using silicon without any barrier material.

The main part of the Li stressing procedure begins with step 8; the steps 8-10 were repeated ten times. The sample was again exposed to a current of maximum $712 \mu \mathrm{A}$ up with a limitation in voltage of $20 \mathrm{mV}$ for $6 \mathrm{~h}$, i.e., until $5 \mathrm{mAh}$ was reached. Subsequently, a discharging step with a voltage limitation of $1 \mathrm{~V}$ was applied. By analyzing the overall charge capacity, information on the performance of the barrier can be gathered. After the stressing procedure the cells were allowed to rest for $24 \mathrm{~h}$, then they were disassembled; after that the samples were washed with diethyl carbonate solvent and dried. All electrochemical tests were carried out at a temperature of $22^{\circ} \mathrm{C}$.

Depth profiles. Li depth profiles were observed by means of secondary ion mass spectroscopy with a time-offlight detector from ION-TOF GmbH (Münster, Germany). In Table 3 the measurement parameters for the barrier investigations are summarized.

Fitting. The Li profile in the W-Ti barrier was fitted via a numerical analysis following the Crank-Nicolson method; the diffusion coefficient was optimized via the Levenberg-Marquardt algorithm [17]. Assuming a thin film as Li source the initial condition for non-steady state diffusion in $x$ dimension is given by

$c(x, t)=M \times \delta(x)$ at $t=0$

$M$ denotes the number of diffusion particles per area and $\delta(x)$ represents the Dirac delta function. If the diffusion
Table 3 ToF-SIMS measurement conditions for the barrier investigations in positive ion measurement mode at room temperature

\begin{tabular}{ll}
\hline ION-TOF: TOF.SIMS & \\
\hline Sputter gun & $\mathrm{O}_{2}^{+}: 2 \mathrm{keV}, 600 \mathrm{nA}$ \\
Primary gun & $\mathrm{Bi}_{3}^{+}: 25 \mathrm{keV}$, \\
& $0.6-0.8 \mathrm{pA}$ \\
& pulsed \\
Cycle time & $65 \mu \mathrm{s}$ \\
$\mathrm{e}^{-}$Flooding & Active \\
\hline
\end{tabular}

source is deposited initially onto the sample surface and diffuses into bulk material the solution of the underlying diffusion equation is

$c(x, t)=\frac{M}{\sqrt{\pi D t}} \mathrm{e}^{-\frac{x^{2}}{4 D t}}$

In case that at $t=0$ the diffusing species has an initial distribution with $c=c_{0}$ for $x<0$ and $c=0$ for $x>0$ it can be interpreted as continues distribution of an instantaneous, planar source. The solution can be thought as the integral of all infinitesimal planes resulting from the spatial distribution of the diffusing species. With introduction of the complementary error function the diffusion equation is given by

$c(x, t)=c_{0} \operatorname{erfc}\left(\frac{x}{2 \sqrt{D t}}\right)$

\section{Results and discussion}

Figure 2 shows SEM cross-sections of the three barrier materials as deposited. For all materials investigated, a homogeneous coverage with a thickness of $50 \mathrm{~nm}$ was achieved. The W-Ti layer showed maximal roughness of $R_{\mathrm{a}}=2.5 \mathrm{~nm}$. The other layers are characterized by smaller $R_{\mathrm{a}}$ values being below the sensitivity of the profilometer used. Figure 1a shows the TaN barrier deposited, for which polycrystalline structure could be identified from SEM. The microstructure of TiN is depicted in Fig. 1b whereas the W-Ti alloy layer (Fig. 1c) shows a more pronounced columnar structure. Such columnar microstructures might provide efficient pathways for the lithium ions near the grain boundaries deteriorating the respective properties of the barrier.

The surface stress of the barrier layers was determined by wafer bow measurements and evaluated by means of the Stoney equation as mentioned above. Measurements of the stress of the layers lead to pressure values ranging from $+3.2 \times 10^{8}$ to $-1.9 \times 10^{9} \mathrm{~Pa}$ (see Table 4 ). High positive (tensile stress) or negative (compressive stress) values 

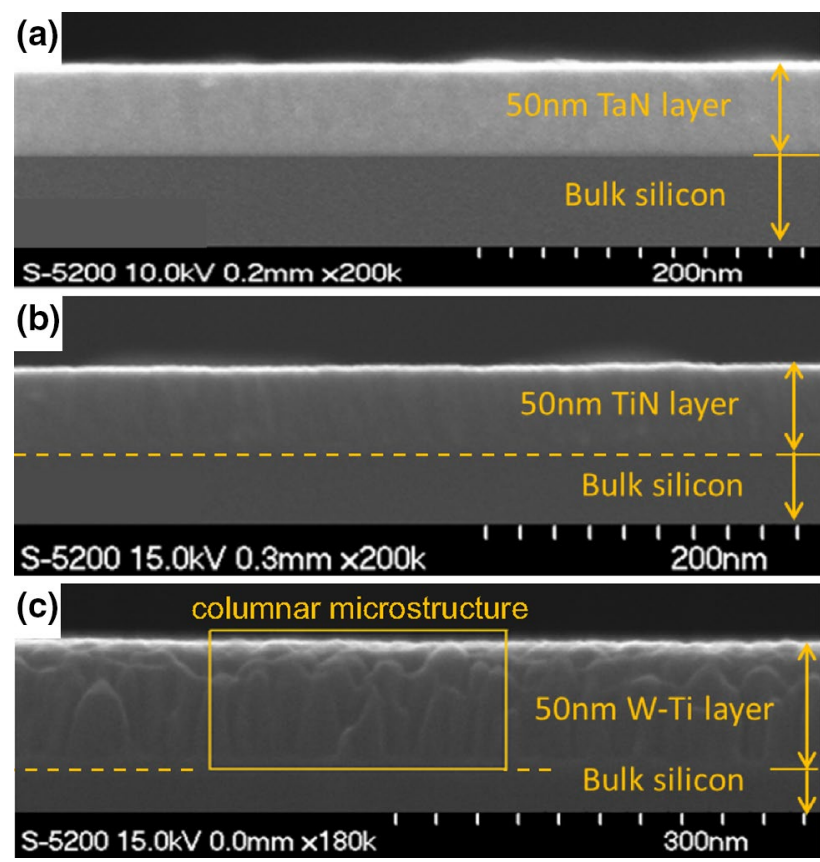

Fig. 2 SEM cross-sections of a the TaN layer (50 nm in thickness) revealing a microcrystalline structure, $\mathbf{b}$ the TiN layer $(50 \mathrm{~nm})$ and $\mathbf{c}$ the $\mathrm{W}-\mathrm{Ti}$ alloy layer $(50 \mathrm{~nm}$ in thickness)characterized by a columnar structure. The barriers were deposited on a (100) oriented silicon substrate

indicate a high concentration of dislocations or defects introduced during the deposition process [18]. Consequently, this might lead to reduced performance of the barrier. Whereas $\mathrm{W}-\mathrm{Ti}$ and TiN showed compressive stress, $\mathrm{TaN}$ exhibited values pointing to tensile stress.

\subsection{Cyclic voltammetry}

To determine the electrochemical activity of the barrier materials cyclic voltammetry (Fig. 3) measurements between $50 \mathrm{mV}$ and $1.5 \mathrm{~V}$ versus $\mathrm{Li} / \mathrm{Li}^{+}$were carried out. The two refractory metal nitrides (cf. the curves drawn in black and blue color) showed no distinct peaks up to $1.5 \mathrm{~V}$. This points to a sufficiently high electrochemical stability of the corresponding surfaces. On the other hand, for the tungsten titanium alloy (see the red curve in Fig. 3) two shallow reduction peaks were detected. As no corresponding oxidation reaction can be determined at the step speed of $30 \mu \mathrm{V} \mathrm{s}^{-1}$ applied, a CV measurement with increased scan rate was performed: peaks showed up at 0.37 and $0.65 \mathrm{~V}$, respectively; moreover, an oxidation peak was detectable. In contrast to the nitride, the pure metallic tantalum revealed two pronounced reduction peaks and a broad oxidation peak directly pointing to lithiation and delithiation of the barrier. It is worth to mention that in both cases the voltage difference between oxidation and reduction peak is relatively large pointing to slow charge transfer kinetics; the peak current ratio, being much larger than one, as well as the dependence of the peak current on the scan rate points to irreversible processes taking place [19].

\subsection{Charging/discharging}

To evaluate the efficiency of the barrier materials to block $\mathrm{Li}$ ion migration across the different layers the materials were subjected to charge/discharge tests in Si-based batteries. We used the standardized battery cycling program mentioned above. The capacities referring to charging and discharging the cells were recorded as a function of cycle number. Figure 4 shows the change of the current (a) and the voltage (b) of the test cells (see step 8 of Table 2). At a process time of $121 \mathrm{~h}$ a charging current of $712 \mu \mathrm{A}$ was applied with a maximum allowed decrease in voltage of $20 \mathrm{mV}$. For all samples the limit in current could not be reached and the $20 \mathrm{mV}$ threshold applied limits the corresponding currents. After another $6 \mathrm{~h}$ the discharging step was started with the potential limited to $1 \mathrm{~V}$. The silicon sample remained at this potential for several hours before relaxation to the open circuit voltage (OCV) took place. Although the samples with the barriers revealed very small voltage drops, their electrical relaxation behavior turned out to be differently. After the final charge/discharge cycle a 24-h rest step was applied after which all samples reached their OCVs.

Figure 5 shows the charge and the discharge capacities of the cells with the barriers as well as those of the reference cell without any barrier. The (charge) capacities directly correspond to the efficiency of the barrier materials tested. The lower the capacities measured the more efficient

Table 4 Summary of the structural and mechanical properties of the barrier layers tested

\begin{tabular}{llllll}
\hline Barrier material & Abbreviation & Modification/composition & $\begin{array}{l}\text { Thickness } \\
(\mathrm{nm})\end{array}$ & Layer appearance & Built-in stress (Pa) \\
\hline Tungsten-titanium & W-Ti & W-alloy $(20$ at\% Ti) & 50 & Columnar & $-1.5 \times 10^{9}$ \\
Titanium nitride & TiN & Cubic (1:1) & 50 & Columnar & $-1.3 \times 10^{9}$ \\
Tantalum nitride & TaN & Cubic (1:1) & 50 & Polycrystalline & $+3.2 \times 10^{9}$ \\
Tantalum & Ta & Cubic & 50 & Polycrystalline & $-2.2 \times 10^{9}$ \\
\hline
\end{tabular}




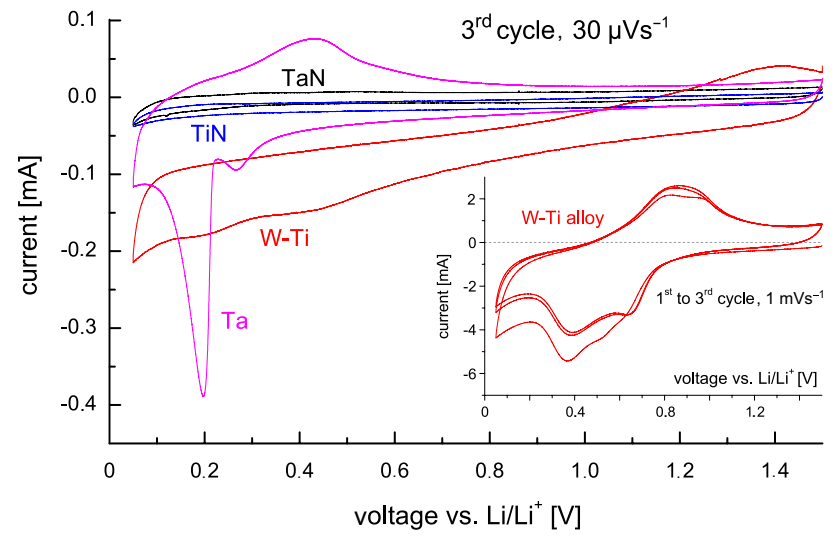

Fig. 3 Cyclic voltammograms of the Li ion test cells equipped with the four barrier materials tested. The scan rate was $30 \mu \mathrm{Vs}^{-1}$; in each case the voltammograms show the 3 rd cycle. The inset displays the cyclic voltammograms for W-Ti recorded at an increased scan rate of $1 \mathrm{~m} \mathrm{Vs}^{-1}$. See text for further details

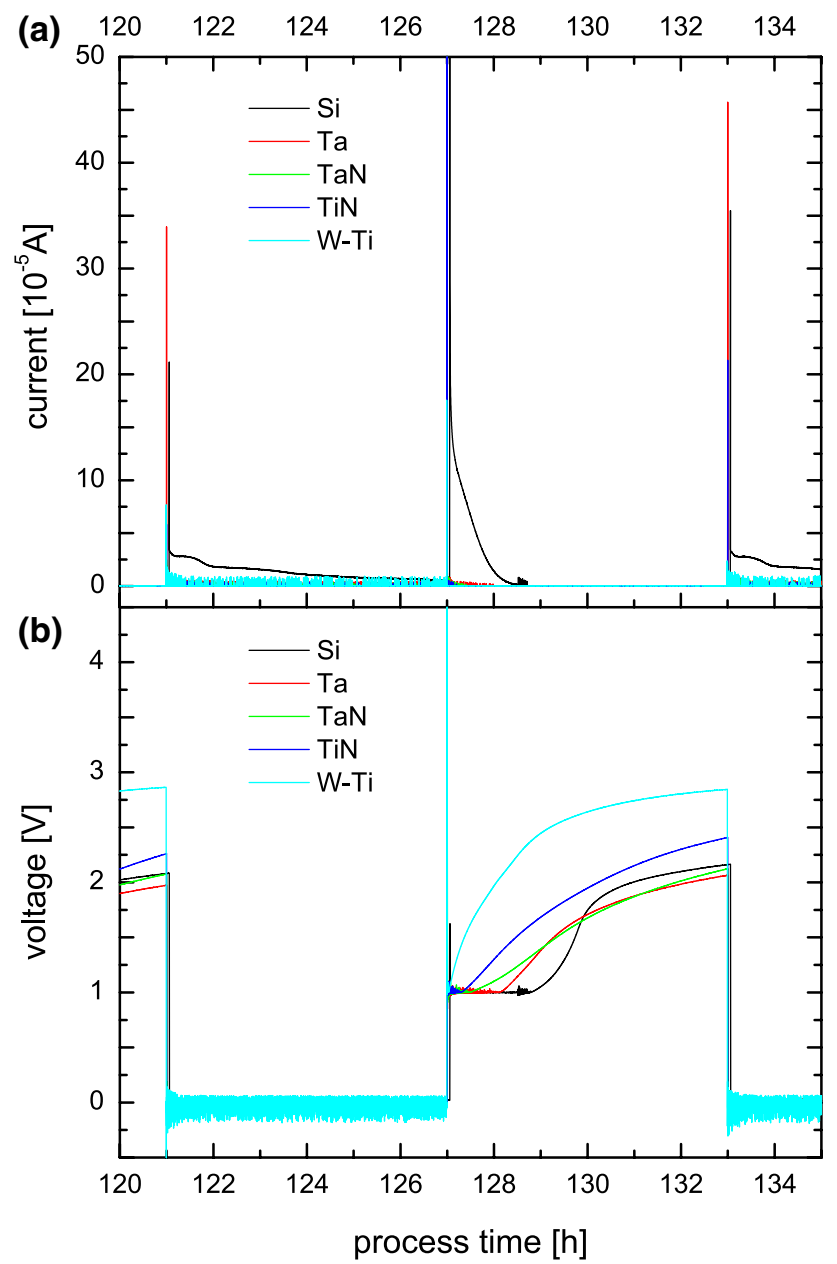

Fig. 4 Illustration of the voltage response after the 8th charging/discharging cycle of the Li cells; $\mathbf{a}$ current and $\mathbf{b}$ voltage profiles as a function of time. See text for further explanation the barrier is, i.e., the more effectively the barrier blocks $\mathrm{Li}$ ion transfer. The reference cell without any barrier layer ( $\mathrm{Si}$, see right axis of Fig. 5) served to illustrate the blocking effect of the barriers. The cell having no barrier inside shows a continuous increase in capacity during cycling finally reaching values of ca. $235 \mu \mathrm{Ah} \mathrm{cm}^{-2}$ (cycle no. 10). Upon discharge (see the dotted line) a very similar behavior is seen although the corresponding capacities are slightly lower $\left(216 \mu \mathrm{Ah} \mathrm{cm} \mathrm{cm}^{-2}\right)$. This difference can be explained by a partially irreversible uptake of $\mathrm{Li}$ ions by silicon as well as the formation of the passivating SEI [20]. Mechanical destruction, i.e., detachment of lithiated silicon could also lead to irreversible capacity losses. All cells equipped with barriers showed charging capacities below $9 \times 10^{-3}$ $\mu \mathrm{Ah} \mathrm{cm} \mathrm{cm}^{-2}$ (see left axis in Fig. 5), i.e., almost two orders of magnitude lower than the charge capacity of the cell without any barrier. Generally speaking, expect for the W-Ti and $\mathrm{Ta}$ system the barriers are able to block $\mathrm{Li}$ ion transport but there are noteworthy differences.

Despite its columnar microstructure the best performance in terms of any ability to block $\mathrm{Li}$ ion transfer was observed for the TiN barrier (see Fig. 2b). In the first cycle the capacity observed under charging conditions shows a larger irreversible value as compared to the other cycles. This behavior can be explained by the formation of a passivating layer that consumes some electrolyte, conductive salt and, thus, lithium ions. It is, thus, not necessarily related to the efficiency of the barrier. Most likely, the composition of the layer formed cannot be compared with the SEI at Si surfaces [21]. The corresponding discharge curve of the cell equipped with TiN reveals a capacity being lower than $1 \times 10^{-3} \mu \mathrm{Ah} \mathrm{cm}^{-2}$; because of the restrictions in sensitivity of the test equipment used; the limit was $75 \mathrm{nA}$, thus, very low currents cannot be determined with high precision. The capacity of a TiN layer is supposed to depend linearly on the layer thickness, for $\mathrm{TiN}$ values of $0.02 \mathrm{Li}$ per formula were calculated [14]. Here, considering the discharge capacity experimentally a value of $0.002 \mathrm{Li}$ atoms per TiN formula unit was found which is significantly lower than the calculated result (see Table 5). The value corresponding to the charge capacity turned out to be only slightly higher $(0.003 \mathrm{Li})$. The difference points to some irreversible loss of $\mathrm{Li}$ at the barrier. These ions might reduce the efficiency of the blocking layer.

Cells with Ta and TaN show higher capacities while the discharge capacities are, at least for TaN, again below the detection limit. Once again some amount of Li was irreversibly consumed during charging. In both cases the charge capacity slightly increases when the cells are cycled for more than three times. We found that during charging the $\mathrm{Li}$ uptake of $\mathrm{Ta}$ is ca. $0.09 \mathrm{Li}$, this value is in good agreement with literature data [14]. During discharging the value reduces to $0.02 \mathrm{Li}$ per Ta. Thus, we assume that the 
Fig. 5 Charge and discharge capacities (see left axis) of the cells equipped with the barriers investigated (Ta, TaN, TiN, WTi) that should block lithiation of Si. The cell without any barrier is shown for comparison, too (see the capacities on the right axis). The lines represent guides to the eye. Note the huge difference in charge capacities indicated by the two axis

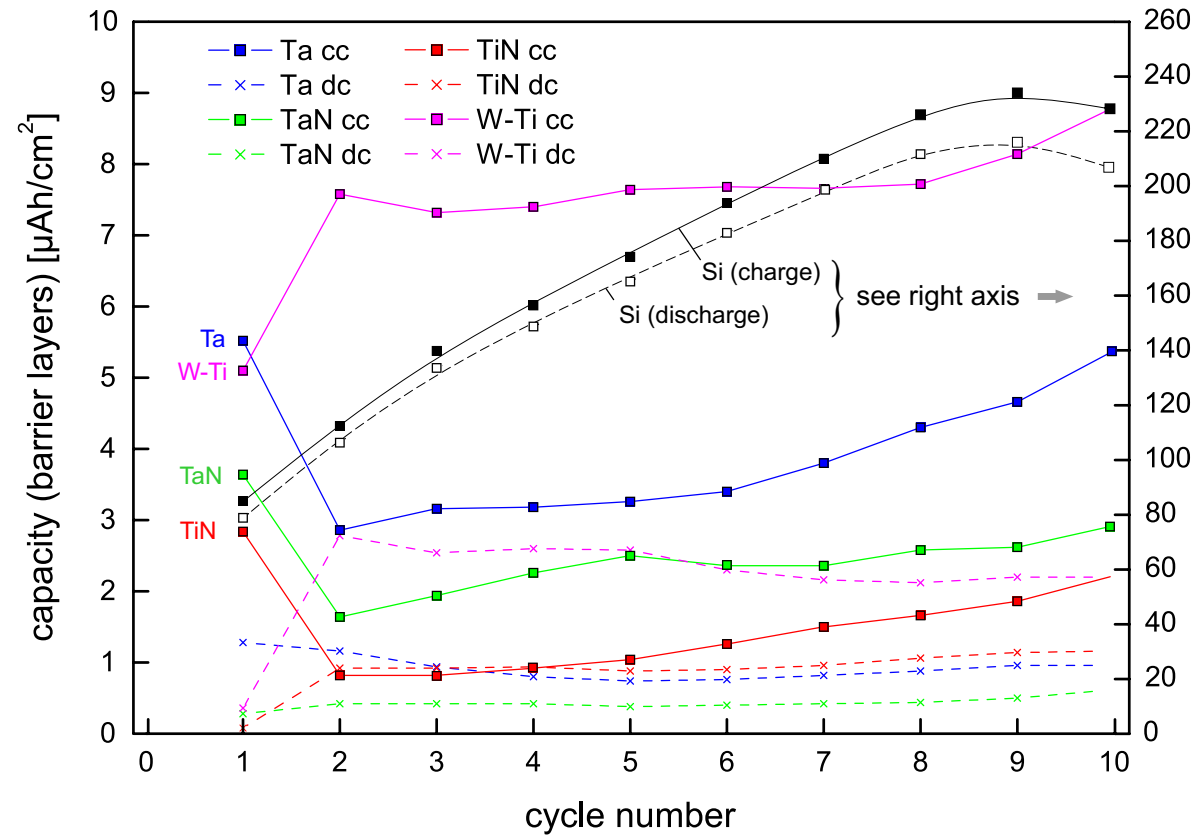

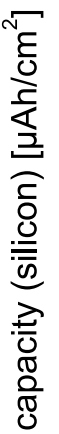

Table 5 Charge and discharge capacities (average values) and Li uptake per formula unit

\begin{tabular}{lllll}
\hline & $\begin{array}{l}\text { Charge capacity } \\
(\mu \mathrm{Ah})\end{array}$ & $\begin{array}{l}\text { Discharge capacity } \\
(\mu \mathrm{Ah})\end{array}$ & $\begin{array}{l}\text { Number of Li per formula } \\
\text { unit (charge) }\end{array}$ & $\begin{array}{l}\text { Number of Li per } \\
\text { formula unit (dis- } \\
\text { charge) }\end{array}$ \\
\hline $\mathrm{TiN}$ & $7.6 \times 10^{-4}$ & $4.5 \times 10^{-4}$ & 0.003 & 0.002 \\
$\mathrm{Ta}$ & $1.9 \times 10^{-3}$ & $5.7 \times 10^{-4}$ & 0.088 & 0.021 \\
$\mathrm{TaN}$ & $1.2 \times 10^{-3}$ & $2.2 \times 10^{-4}$ & 0.051 & 0.009 \\
$\mathrm{~W}-\mathrm{Ti}$ & $3.5 \times 10^{-3}$ & $1.1 \times 10^{-3}$ & 0.143 & 0.042 \\
\hline
\end{tabular}

charging-discharging procedure is only partially reversible affecting the overall efficiency of the barrier. For TaN, values of $0.05 \mathrm{Li}$ per TaN (charging) and $0.009 \mathrm{Li}$ (discharging) were found.

Compared to the other barrier layers $\mathrm{W}-\mathrm{Ti}$ shows the highest charge and discharge capacities. Also in this case an irreversible redox reaction took place. Up to $25 \%$ of the charge carriers can be reversibly stored in the cell with a W-Ti barrier. Therefore, W-Ti seems to be an inadequate barrier in lithium-ion batteries; the uptakes for Li per formula unit are 0.15 (charging) and 0.04 (discharging), respectively.

Mass Spectrometry. Time of flight-secondary ion mass spectroscopy is a powerful tool to determine diffusion profiles in thin $(<1 \mu \mathrm{m})$ layers. Most importantly, measurement artifacts have to be carefully excluded. For example, the roughness of the surface may broaden interfaces. Another more problematic measurement failure is the so-called tailing caused by ion mixing during sputtering [22]. To distinguish which profile originates from diffusion and which one stems from ion mixing comparative measurements on samples with a non-diffusive component are necessary.
An inherent behavior of a silicon surface being in contact with an electrolyte is the SEI formation. The SEI is a mixture of organic and inorganic components. Especially for organic components diffusion into the layer material can be regarded as negligible. Therefore, such components can be used as an internal reference to study and to rule out the influence of ion mixing.

There is still another artefact known for its high impact for measurements of positively charged secondary ions. Because of the positive charge of the primary ions the analyte is pushed deeper into the bulk material. In particular, this is the case when one deals with an electric isolator, as $\mathrm{TaN}$ is. An increasing signal at the subsequent interface gives a hint to this phenomenon. In the next section we will present the results of ToF SIMS experiments on samples which were electrochemically charged and discharged for 10 cycles.

In the case of TaN (see Fig. 6a) a high intensity for $\mathrm{Li}^{+}$ and $\mathrm{CHF}^{+}$, which represents the SEI layer, can be found at the beginning, see the sputter time up to $40 \mathrm{~s}$. While the $\mathrm{Si}$ signal is negligible the intensity for the barrier layer $\mathrm{Ta}^{+}$continuously increases and reaches a plateau at $180 \mathrm{~s}$. 

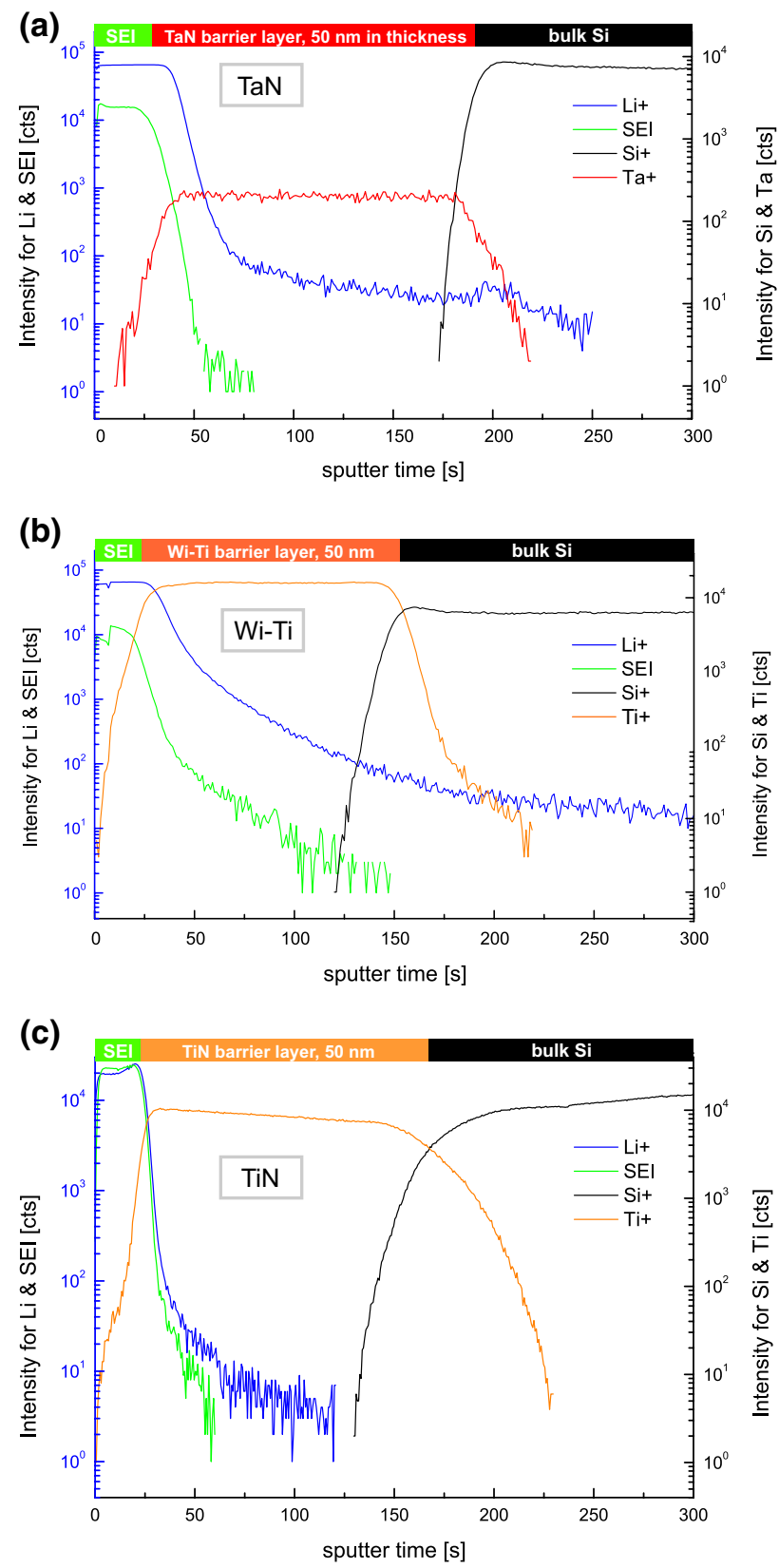

Fig. 6 ToF-SIMS depth profile of layers of a TaN, $(50 \mathrm{~nm}) \mathbf{b}$ the WTi alloy $(50 \mathrm{~nm})$ and $\mathbf{c}$ TiN $(50 \mathrm{~nm})$ deposited on a silicon substrate $(100 \mathrm{~nm})$

A sputter period of approximately $140 \mathrm{~s}$ corresponds to the 50-nm thick TaN layer. In general, each material each material behaves differently which makes a correct depth calibration almost impossible.

Note that the $\mathrm{Li}^{+}$intensity remains on a relatively high level in the region of the TaN barrier; this behavior has, most probably, ascribed to the artefact described above and seems to be caused by the low conductivity of TaN. A slight peak at the silicon interface can be noticed before the $\mathrm{Li}^{+}$signal decreases to the noise level. The slope of the
$\mathrm{Li}^{+}$signal at about $50 \mathrm{~s}$ is very similar to that of the signal corresponding to the SEI, which reached the noise level shortly after the Ta signal has reached its plateau regime. The observations indicates that the barrier material seems to effectively block $\mathrm{Li}$ ion transport. Thus, ToF SIMS indeed gives evidence that TaN might be used as a suitable barrier.

For the TiN barrier (see Fig. 6c) we observed a sharp drop of both the $\mathrm{Li}^{+}$signal and the SEI signal after ca. $30 \mathrm{~s}$; simultaneously a rise of the $\mathrm{Ti}^{+}$signal is seen. This drop points to a narrow interface region. The $\mathrm{Li}^{+}$level in the barrier is significantly lower compared to the situation seen for TaN. Most likely, this difference has to be ascribed to the different conductivities of the two barrier materials; the electrical resistance is $20 \mu \Omega \mathrm{cm}$ for TiN and $135 \mu \Omega \mathrm{cm}$ for TaN, respectively. Based on the ToF-SIMS traces we identify both TaN and TiN, in particular, as relatively dense barrier materials.

For W-Ti (see Fig. 6b) the ToF-SIMS signal for $\mathrm{Li}^{+}$ behaves quite different compared to tantalum nitride (Fig. 6a) and titanium nitride (Fig. 6c). We noticed that the signal does not follow the SEI signal in shape; in particular, the slopes of the two signals differ at the beginning. Most importantly, the $\mathrm{Li}^{+}$signal does not reach the noise level neither in the barrier nor in the region of bulk silicon.

For the Ta layer our CV experiments indicate that Ta reacts with $\mathrm{Li}$. After the electrochemical test procedure the surface showed planar dendrites. The visualization of the ion signal of our ToF SIMS experiments (cf. Fig. 7a) also reveals that tantalum electrochemically reacts with $\mathrm{Si}$ as a high silicon concentration could be determined. From the corresponding ToF-SIMS depth profile shown in Fig. $7 \mathrm{~b}$ it can, thus, be concluded that Ta is not a suitable barrier since it reacts with both parts of the diffusion couple.

To quantify Li in-diffusion for the W-Ti layer in Fig. 8 the smoothed $\mathrm{Li}$ profile determined via ToF-SIMS (see black line) is plotted. For comparison, the profiles obtained by approximating the signal with a Gaussian solution of Fick's second law (see red line) as well as the complementary error function (see blue line) is also shown. As expected, the experimentally probed $\mathrm{Li}$ ion diffusion profile cannot be approximated by these functions properly. They represent profiles with ideal boundary conditions. Several origins may explain the deviation from, e.g., an ideal Gaussian profile. For instance, the ToF-SIMS measurement itself might lead to a distorted shape of the signal as mentioned above. Moreover, the charge/discharge loop used to simulate battery conditions is another source of trouble. During each discharge step Li ions are pulled back leaving areas depleted in $\mathrm{Li}$ behind. Hence, the $\mathrm{Li}$ profile becomes steeper as one would expect for a pure bulk diffusion process. The fits shown in Fig. 8 were used to roughly estimate the underlying diffusion coefficients. The two 

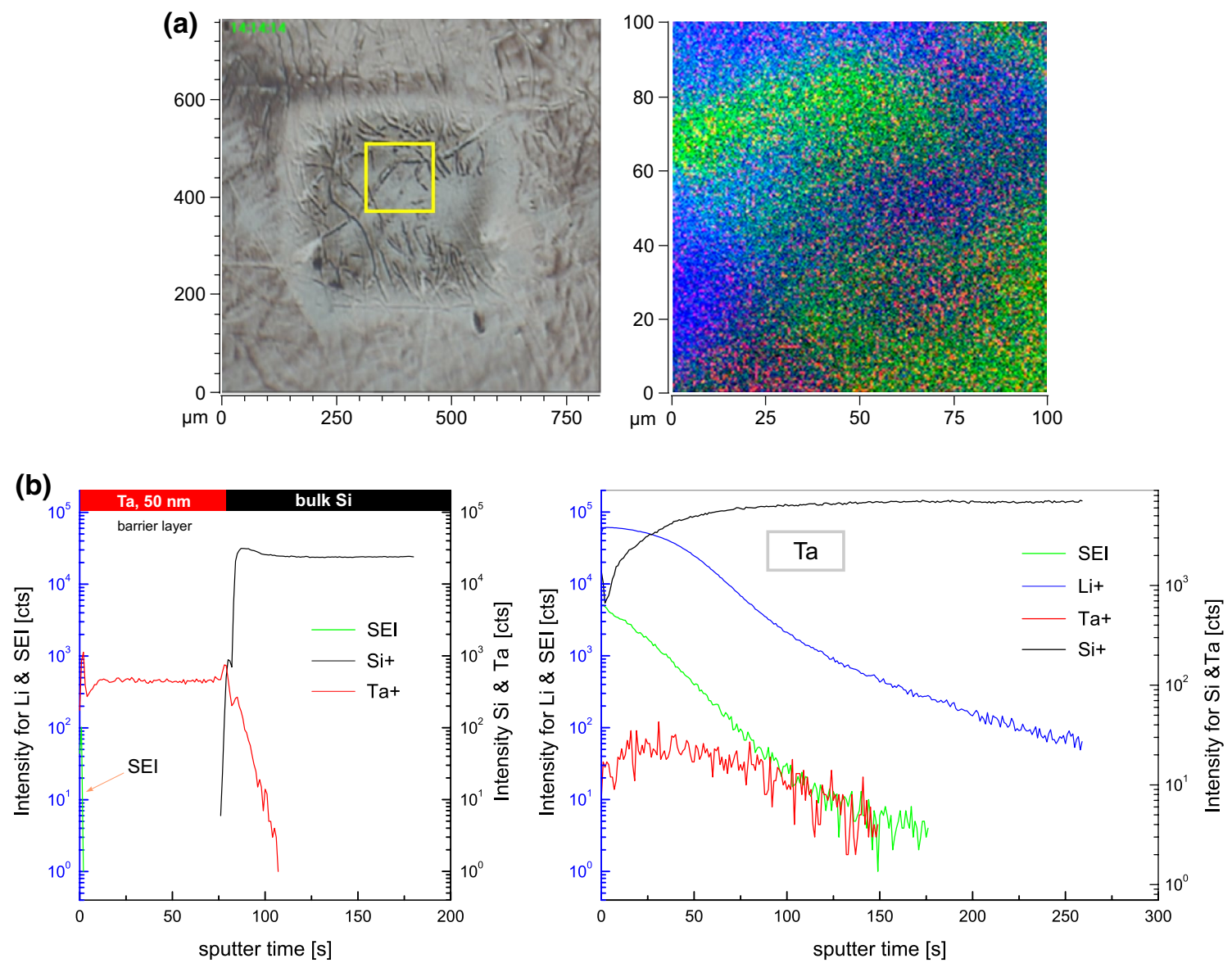

Fig. 7 a The sputter crater after ToF-SIMS measurement and ion distribution of Si (green), Ta (red) and Li (blue). b ToF-SIMS measurement of the initial tantalum layer (left) and the transformed tantalum layer (right). (Color figure online)

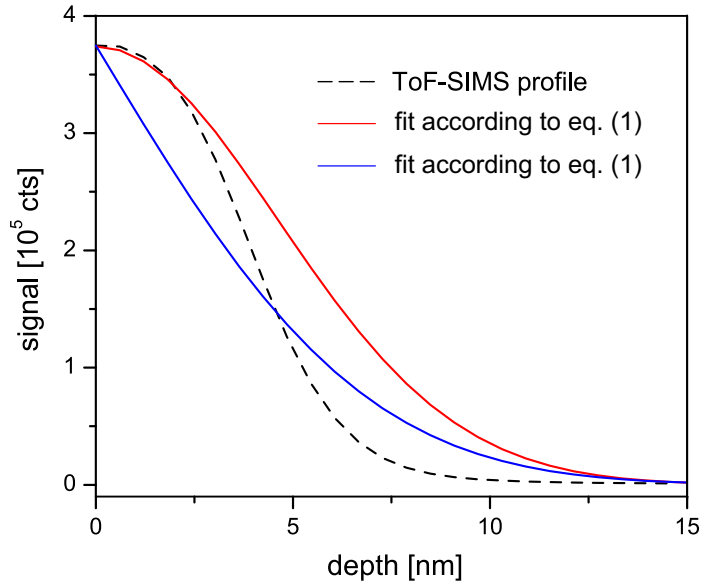

Fig. 8 Comparison of the ToF-SIMS depth profile of Li diffusion in W-Ti alloy with two solutions of Fick's law. For comparison, the solid lines represent profiles according to Eqs. (1) and (2), see above. Both profiles, although considerably different from the experimental response, suggest that the diffusion coefficient is in the order of $10^{-19} \mathrm{~cm}^{2} \mathrm{~s}^{-1}$ functions shown are characterized by the following values $D=1.6 \times 10^{-19} \mathrm{~cm}^{2} \mathrm{~s}^{-1}$ (error function) and $D=2.2 \times 10^{-19}$ $\mathrm{cm}^{2} \mathrm{~s}^{-1}$ (Gaussian function), respectively. Taken together, in contrast to TaN and TiN the results for $\mathrm{W}-\mathrm{Ti}$ clearly show that it is not a suitable barrier to block lithium ion migration in silicon-based microbatteries. For comparison, $\mathrm{Li}$ self-diffusion in amorphous $\mathrm{Li}_{1.5} \mathrm{Si}$ prepared electrochemically has to be characterized by $D$ values in the order of $10^{-9} \mathrm{~cm}^{2} \mathrm{~s}^{-1}$ [23].

\section{Conclusions}

For the development of integrated lithium-ion batteries for Si-based devices the encapsulation of the active battery components is mandatory. Tantalum, tantalum nitride, titanium nitride as well as a tungsten titanium alloy were tested for their capability to serve as efficient barriers against $\mathrm{Li}$ ion in-diffusion. By means of Swagelok cell assemblies the barrier materials were electrochemically stressed and characterized. The suppression of Li diffusion and reaction with 
the help of these barriers was determined with cyclic voltammetry and ToF-SIMS, in particular.

Although used as barrier against $\mathrm{Cu}$ in-diffusion, here electrochemical tests and ToF-SIMS showed that the W-Ti alloy layer with a thickness of $50 \mathrm{~nm}$ does not serve as a reasonable barrier to protect the device from $\mathrm{Li}$ ion contamination. The corresponding coefficient estimated from SIMS was in the order of $2 \times 10^{-19} \mathrm{~cm}^{2} \mathrm{~s}^{-1}$. In the case of tantalum, electrochemical activity with lithium was clearly revealed; therefore, it is also not suitable to act as barrier material. TiN and TaN layers $(50 \mathrm{~nm})$, on the other hand, were identified as promising barriers for lithium-based microbatteries with $\mathrm{Si}$ anodes. The current results and findings presented may enable the integration of such miniaturized batteries as power supplies for microelectromechanical systems in single crystalline silicon.

Acknowledgements Open access funding provided by Graz University of Technology. Financial support by Infineon Technologies Austria AG, the Federal Ministry of Science, Research and Economy and the National Foundation for Research, Technology and Development is gratefully acknowledged. We thank the workgroups of Prof. Hutter and Prof. Limbeck (Vienna University of Technology) for the access to analytical equipment. Moreover, the support of NAWI Graz is gratefully acknowledged.

Funding Funding was provided by the CDG (Christian Doppler Forschungsgesellschaft).

Open Access This article is distributed under the terms of the Creative Commons Attribution 4.0 International License (http:// creativecommons.org/licenses/by/4.0/), which permits unrestricted use, distribution, and reproduction in any medium, provided you give appropriate credit to the original author(s) and the source, provide a link to the Creative Commons license, and indicate if changes were made.

\section{References}

1. D.C. Walther, J. Ahn, Progr. Energy Combust. Sci. 37, 583-610 (2011)
2. J.W. Long, B. Dunn, D.R. Rolison, H.S. White, Chem. Rev. 104, 4463-4492 (2004)

3. M. Armand, J.M. Tarascon, Nature 451, 652-657 (2008)

4. J.F.M. Oudenhoven, L. Baggetto, P.H.L. Notten, Adv. Energy Mater. 1, 10-33 (2011)

5. S.D. Jones, J.R. Akridge, J. Power Sources 43-44, 505-513 (1993)

6. F. Albano, Y.S. Lin, D. Blaauw, D.M. Sylvester, K.D. Wise, A.M. Sastry, J. Power Sources 185, 1524-1532 (2008)

7. D. Golodnitsky, V. Yufit, M. Nathan, I. Shechtman, T. Ripenbein, E. Strauss, S. Menkin, E. Peled, J. Power Sources 153, 281-287 (2006)

8. S. Ferrari, M. Loveridge, S.D. Beattie, M. Jahn, R.J. Dashwood, R. Bhagat, J. Power Sources 286, 25-46 (2015)

9. H. Nienhaus, H. Karacuban, D. Krix, F. Becker, U. Hagemann, D. Steeger, R. Bywalez, C. Schulz, H. Wiggers, J. Appl. Phys. 114, 034310 (2013)

10. M. Green, E. Fielder, B. Scrosati, M. Wachtler, J.S. Moreno, Electrochem. Solid-State Lett. 6, A75-A79 (2013)

11. M. Sternad, M. Forster, M. Wilkening, Sci. Rep. 6, 31712 (2016)

12. K. Hoeppner, M. Ferch, M. Eisenreich, K. Marquardt, R. Hahn, P. Mackowiak, B. Mukhopadhyay, H.D. Ngo, R. Gernhardt, M. Toepper, K.D. Lang, J. Phys. Conf. Ser. 476, 012086 (2013)

13. M.A. Nicolet, Thin Solid Films 52, 415-443 (1978)

14. L. Baggetto, J.F.M. Oudenhoven, T. van Dongen, J.H. Klootwijk, M. Mulder, R.A.H. Niessen, M.H.J.M. de Croon, P.H.L. Notten, J. Power Sources 189, 402-410 (2009)

15. G. Stoney, Proc. R. Soc. A 82, 172-175 (1909)

16. B. Liang, Y. Liu, Y. Xu, J. Power Sources 267, 469-490 (2014)

17. P. Fielitz, G. Borchardt, M. Schmücker, H. Schneider, Solid State Ion 160, 75-83 (2003)

18. L.B. Freund, S. Suresh, Thin Film Materials: Stress, Defect Formation and Surface Evolution. (Cambridge University Press, Cambridge, 2003)

19. G. Henze, Polarographie und Voltammetrie: Grundlagen und analytische Praxis. (Springer, Berlin, 2001)

20. H. Bülter, M. Sternad, E.S. dos Sarinha, J. Witt, C. Dosche, M. Wilkening, G. Wittstock G, J. Electrochem. Soc. 163, A504A512 (2016)

21. P. Verma, P. Maire, P. Novák, Electrochim. Acta 55, 6332-6341 (2010)

22. A. Benninghoven, F.G. Rüdenauer, H.W. Werner, Secondary Ion Mass Spectrometry. (Wiley, NewYork, 1987)

23. A. Dunst, M. Sternad, V. Epp, M. Wilkening, J. Phys. Chem. C 119, 12183-12192 (2015) 